\title{
Neurowissenschaften und Verantwortung
}

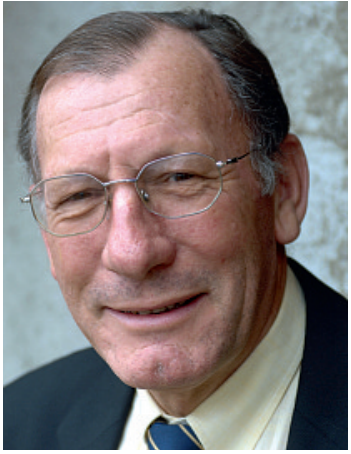

Jean Martin
Der freie Wille ist einer der grossen Gegenstände der Philosophie. Neue Erkenntnisse in den Neurowissenschaften haben einmal mehr zu der Frage bewogen, bis zu welchem Grad wir wirklich selbstbestimmt handeln oder aber durch äussere und innere Gegebenheiten, die wir nicht kontrollieren, bestimmt werden. Die juristische Lehre und Praxis wären in ihren Grundfesten erschüttert, wenn das Konzept der strafrechtlichen Verantwortung des aus freiem Willen handelnden Menschen in Frage gestellt würde. Nützliche Anhaltspunkte zu diesem Thema liefert ein Werk, das aus einer Tagung von Juristen und Neurowissenschaftlern unter Schirmherrschaft der AAAS (American Association for the Advancement of Science) hervorgegangen ist [1]. Hier einige Zitate (in eigener Übersetzung) und Anmerkungen dazu:

Zunächst ein Gedanke von Greely darüber, was im Grunde das Ich ausmacht: «Ich bin möglicherweise weit mehr mein Geist und mein Gehirn als meine Gene. Meine Gene sind nicht ich. Aber mein Geist, mein Gehirn, das sind vielleicht ich. Wenn nun viele Menschen denken, dass ihr Geist die Essenz dessen ausmacht, was sie sind, könnte es auf geringere Widerstände stossen, wenn Menschen anhand von neurowissenschaftlichen Daten beurteilt werden, als wenn man nach genetischen Daten urteilt.» Eine Fragestellung, die der klassischen Debatte um nature versus nurture nahesteht. Bedenkenswert auch die von Ramachandran angesprochene Möglichkeit, «dass unser bewusster Geist zwar nicht vollkommen frei ist, zu sagen «Ich will〉, wohl aber, zu sagen 〈Ich will nicht». Der freie Wille würde demnach eine Art Vetorecht ...

Zur Bedeutung der neuesten Ergebnisse der neurowissenschaftlichen Forschung (Gazzaniga und Steven): «Unserer Ansicht nach können die Neurowissenschaften nur sehr wenig zum Verständnis der Verantwortung beisteuern - kein Pixel eines Gehirnscans wird jemals etwas über Schuld oder Nichtschuld aussagen können [...]. Das Konzept der Verantwortung ist ein soziales Konstrukt, das innerhalb der Regeln der Gesellschaft existiert und nicht in der neuronalen Struktur des Gehirns angelegt ist.» Nach Einschätzung dieser Autoren ist keine Abschwächung des Konzepts der strafrechtlichen Verantwortung zu erwarten: «Es ist wichtig, sich klarzumachen, dass letztlich, selbst wenn die Ursächlichkeit einer Handlung (sei es eine Straftat oder sonstige Handlung), auf Abläufe im Gehirn zurückgeführt wer- den kann, dies nicht bedeutet, dass der Handelnde von Schuld freigesprochen wird. Die wissenschaftliche Datenlage deutet darauf hin, dass das Gehirn unsere Taten steuert, aber nicht unsere Persönlichkeit. Man kann das Gehirn als ein mehr oder weniger automatisch funktionierendes Instrument wie ein Uhrwerk betrachten, während wir als Menschen in der Regel frei sind, über unsere Zukunft zu bestimmen.» (siehe hierzu auch [2, 3]).

Ein anderer Gedanke lautet, dass der gesellschaftliche Rahmen es leisten kann, neue Erkenntnisse aufzugreifen, ohne seine Grundsätze aufzugeben oder seine Daseinsberechtigung zu verlieren: «Die Entwicklungen in den Neurowissenschaften könnten sich durchaus substantiell darauf auswirken, wie das Gesetz die Menschen und ihre Handlungen sieht, doch das Rechtssystem sollte in der Lage sein, eine Wissenschaft, auch eine revolutionäre, $\mathrm{zu}$ absorbieren und für sich zu nutzen, ohne seine Grundstruktur auf den Kopf zu stellen.» (Garland).

Eine Anmerkung zu einer Entwicklung, die im Gerichtssaal eine Rolle spielen wird: «Grosse soziale Institutionen - von den Schulen über die Gerichte bis hin zum Arbeitsplatz und Gesundheitswesen - werden sehr von den Tests profitieren, die die neurowissenschaftliche Forschung hervorbringt. Tests sind in der amerikanischen Kultur zum Bestandteil des way of life geworden». Doch bei diesen Tests «besteht die ausgeprägte Tendenz, Fragestellungen stark auf angeblich solide, objektive Kriterien zu reduzieren. Diese Reduktion hat zwei Vorteile: Die Ergebnisse sind konkret, und sie lassen glauben, das weitere Vorgehen sei ganz einfach - wer inadäquate biologische Testergebnisse hat, wird ans Gesundheitssystem verwiesen» (Tancredi). Doch muss man natürlich vorsichtig sein, die Objektivierung und Pathologisierung nicht zu weit zu treiben.

Werden nun die Grenzen immer mehr verschwimmen, gibt es eine Vermischung zwischen dem, wie eine Gesellschaft die Handlungen ihrer Mitglieder und deren Verantwortung dafür bewertet, und dem, was die Neurowissenschaften an Ergebnissen hervorbringen? Man sieht es am Beispiel der Genforschung, wo in der Presse bereits oft diskutiert wird, ob von der Norm abweichende Verhaltensweisen mit genetischer Vorbelastung zusammenhängen. 